\title{
Browsing through the Observing Books of Carloforte
}

\author{
S. Uras \\ CNR, Gruppo Nazionale di Astronomia, UdR Cagliari, 09012 \\ Capoterra, Italy
}

A. Poma and P. Calledda

Stazione Astronomica, 09012 Capoterra (Cagliari), Italy

\section{Introduction}

The history of the Carloforte ILS Station is also the history of all the people who have spent part of their life working there. Table 1 shows the names of these people from the beginning of the service till its end.

Table 1. Observers at the Carloforte ILS Station from 1899 to 1978.

\begin{tabular}{|c|c|c|c|c|c|}
\hline Observer & Interval & N. & Observer & Interval & N. \\
\hline E. Bianchi & Oct $1899-$ Dec 1902 & 4912 & M. Castellano & Oct 1941-Jul 1952 & $\overline{8824}$ \\
\hline G. Ciscato & Oct 1899 - Sep 1903 & 6939 & A. Zinno & Oct 1948 - Apr 1950 & 1107 \\
\hline L. Volta & $\operatorname{Jan} 1903$ - Sep 1908 & 8697 & P. Melchior & Feb 1951 - Mar 1951 & 59 \\
\hline L. Carnera & Nov 1903 - Mar 1909 & 2802 & A. Vergnano & Aug 1951 - Aug 1962 & 13379 \\
\hline G. Silva & Sep 1905 - Nov 1908 & 6776 & P. Perri & Feb 1952 - Sep 1953 & 1653 \\
\hline F. Chionio & Oct 1908 - Nov 1910 & 3043 & E. Fichera & Mar 1952 - Feb 1956 & 3249 \\
\hline G.A. Favaro & Apr 1909 - Jul 1912 & 5072 & S. Aloi & Dec 1954 & 73 \\
\hline G. Bemporad & May 1911 - Apr 1925 & 18443 & C. Moranzino & Oct 1955 - Jun 1970 & 20265 \\
\hline V. Fontana & Jul 1912 - Mar 1920 & 9657 & A. Vassallo & Dec 1955 - Aug 1968 & 1838 \\
\hline M. Frailik & $\operatorname{Sep} 1920$ & 94 & S. Mancuso & Aug 1961 - Oct 1965 & 4686 \\
\hline G. Cecchini & Dec 1920 - Aug 1927 & 6573 & P. Damele & Aug 1967 - Dec 1968 & 658 \\
\hline G. Andrissi & Aug $1926-\operatorname{Dec} 1926$ & 166 & F. Plaisant & Aug $1968-\operatorname{Sep} 1968$ & 139 \\
\hline E. De Caro & Feb 1927 - Apr 1931 & 3705 & M. Missana & Feb 1969 - Sep 1969 & 286 \\
\hline G. Peisino & Aug 1927 - Dec 1929 & 2275 & G. Stefanelli & Apr $1969-\mathrm{Feb} 1971$ & 995 \\
\hline P. Vocca & Nov 1929 - Nov 1932 & 2638 & G.F. Luxoro & Sep 1969 - Oct 1960 & 608 \\
\hline A. Gennaro & Apr 1931 - Mar 1935 & 3915 & E. Proverbio & Dec $1969-$ Jun 1970 & 63 \\
\hline T. Nicolini & Dec 1932 - Sep 1946 & 4314 & N. Borghero & Jul 1970 - Sep 1978 & 1956 \\
\hline E.L. Martin & Mar 1935 - Mar 1938 & 2406 & G. Rivano & Ott $1970-$ Dec 1978 & 7508 \\
\hline J Racugno & Lug 1935 - Ago 1935 & 94 & G.C. Cocco & Nov 1970 - Nov 1978 & 7502 \\
\hline F. Bernard & Jul 1936 - Sep 1938 & 538 & E. Coniglio & Jul 1971 & 8 \\
\hline G. Righini & Mar 1937 - Aug 1939 & 1543 & S. Uras & Jul 1971 - Aug 1975 & 748 \\
\hline R. Ruggiero & Aug 1937 - Oct 1937 & 101 & A. Poma & Aug 1971 & 161 \\
\hline N. Mattana & Nov 1937 - May 1941 & 2135 & G. Muntoni & Aug 1973 & 13 \\
\hline A. Colacevich & Oct 1939 - May 1940 & 321 & M. Serrau & Jul 1978 & 54 \\
\hline N. Missana & Jul 1941 - Apr 1943 & 3427 & & & \\
\hline
\end{tabular}

Running our eyes through the pages of the Carloforte ILS Station Observing books, we can read, beyond the cold figures that refer to the star transits, a lot of notes and comments that allow us to understand the high degree of humanity, scientific reliability and self-abnegation of the observers. Many of them, after their experience at Carloforte, had continued their activity as researchers in other fields of the Astronomy; just as an example, we may cite Bianchi, Volta, Martin, Righini, that respectively became Directors of the Astronomical Observatories 
of Brera, Turin, Trieste, Arcetri. We also may cite Carnera, Cecchini, Nicolini, that played important roles in the Central Bureau of ILS when this one was awarded to Italy. A few on the list were just temporary observers, and their history outside of the Observatory remains unknown for us.

\section{The advent ure begins}

The first page of the observing books has been signed by Emilio Bianchi on October 24, 1899. Bianchi was the assistant of Giuseppe Ciscato, first director of the Station. Both of them were borrowed from the Observatory of Padua.

On December $31^{s t}$, 1899 , while everybody was celebrating the New Year and the new Century, Ciscato was behind his telescope and wrote (Fig. 1, left): "Farewell 1899! I wish that the New Year 1900 would give a lot of wonderful clear nights like this one to all observers of the International Latitude Service." As we can deduce from the Observing books, Christmas, New Year, Easter are workdays for the observers.

At first, a period of 5 to 10 years was foreseen for the ILS activity. However very soon it became clear that the study of the polar motion would require a permanent organization. The ILS managed to survive the First World War and the dissolution of the International Geodetic Association. At Carloforte, the loss in observations due to the war time difficulties had been limited within $15 \%$, thanks to the personal care of Vittorio Fontana, director, and Giulio Bemporad, his assistant. Fontana died two years later; we may say he died while carrying out his duties.

As a footnote to the pages of March 3, 1920, Bemporad writes (Fig. 1, right): "Blunders in the micrometer readings of pairs 35, 39 and 41. These observations are the last ones carried out by the late lamented dr. Vittorio Fontana. Already feverish when carrying out them, he kept to his bed during the same night and he died on March 10, at 2 p.m., due to influenza bronchopneumonia." We want to remark that this note has been written in red, the colour of blood!

Too much zeal? Maybe. But also the awareness of how important should be a night of observations, even only one.

\section{Astronomer and poet}

$\grave{A}$ propos of too much zeal - 10 years went by, from the just told events - this is the title given by Paolo Vocca to one of a hundred or more comments written in verse on the Observing books from 1930 to 1932, while he was director of the Station (fig. 2, left):

(9 p.m.) "The sky is clear, / the wind seems to be strong: / let's try and go!" / (10 p.m.) I come to the tower: / the wind is blowing at seventy!! / (My rheumatism is breaking me!) / What have I to do? / Up there the flag is hoisted!! / Maybe tonight it will crack!! / Even with the wind at seventy / I can low it!! / I try to work, / but the wind don't abate! / I take the hint / and ... (11:30 p.m.) I go back home!! 
Another one is titled Melancholy (Fig. 2, a): Cold, Weariness and Sleep / ganged up tonight! / Is it due to the Spring? / I am seized with an yearning / and a gloomy sadness / is wringing tight my soul. And it's hurting me! / A terrible annoyance / - there is nothing like this! - / is bothering and tormenting me. Why? / Is it due to the Loneliness? / But I got yet accustomed to it! / Maybe this restlessness / is just caused by the aforesaid "ganging"! / Listen to me: will you do a good thing? / Go back home, go to your bed, and don't think any longer of it!

On the same subject, this time in prose (Fig. 3, a): It was worth! After a day of work ( 8 hours of computations!), the sky becoming clear, I set out to the Observatory but I caught the rain in the way. I came back home and resumed my work. The sky became clear again, and I went again up, but I can't do anything! What a weather! Bloody hell!

Two more small stanzas in Fig. 2, b: When the weather drive me mad like tonight / it should be better to go to sleep! / But my "care" says: "Stay here!" / I stay, but what do I do? / I am pitiful! / (It's even cold, in addition!) / In spite of the bad weather, even tonight / I carried out good observations. / Few but magnificent observations, carried out / through many clouds and mists!/ Did you see never... / such a thing, here?!

And finally a few lines regarding... the study of the VZT micrometric screw (Fig. 3, b): As more you get old, as more you do of them: / just your death will make you stop! / Blunders, stupidities, errors as much as you like! / Call them, if you want, “... progressive errors!"

This minimum anthology allows us to imagine both the mood of the writer and the hard work he had to face daily. Many observers, like Vocca, had to experience the loneliness not only by night, while observing, but also during the day, because most of them were young astronomers seconded to Carloforte Station, detached from their habitats and from their families. All of them had to experience the unfavourable weather conditions of Carloforte: cold, strong winds and, specially, a moisture that “... soaks your clothes and gets into your bonds", like some observer wrote on the Observing books.

Finally, we spend a few words to comment on the right side of Fig. 3 . Sardinia is, from a seismic point of view, a very still place. This is one of the reasons that Carloforte has been chosen for the ILS Station. But sometime the echo of a distant earthquake makes the highly sensitive levels of the VZT tilt. Here Vocca is the witness of two seismic events that occurred during his observations: one on August 10, 1931, in China (Fig. 3,a) and the other one on July 23, 1930, in Italy (Fig. 3,d).

\section{Winds of war}

Ten more years went by. Starting from June 10, 1940, Italy become a country at war; up to 1943 observations are normally carried out, but little by little the front is approaching Carloforte. Even on March 6, 1941, N. Mattana (director at that time) writes during the observations: "Some planes are flying over the Station. A military patrol informed me of the air raid warning status. I am compelled to close (the roof) due to enemy aircraft transit" (Fig. 4, 1). 
On January 20, 1943, a momentary cloudiness breaks the Observations of N. Missana; his attention is drawn upon something else, and writes: "Starting from sunset, some aeroplanes are buzzing in the outskirts of Carloforte. Are they searching for any prey?" (Fig. 4, 2). But a few minutes after, the sky becaming clear again, he re-concentrates on his work: "Clear sky... very weak wind from ESE... full Moon...".

Two months later (fig. 4,3) Missana writes: "Air raid warning at 11:10 p.m... I clearly hear the roar of the aeroplane engines... Someone is shooting in the Town... Bengal lights in the direction of St. Antioco Island. At 00 a.m., some fires caused by incendiary bombs in St. Antioco..."

At the beginning of April the situation became even more dramatic; in that occasion Missana wrote (fig 4, 4-5): "Today, around 1 o'clock p.m., several enemy aeroplanes flew over the town at a low altitude. Many incendiary bombs and other small ones have been dropped on the port and on the vicinities of the observatory: 9 killed and 30 injured, excluding soldiers. The house trembled, all the northern windowpanes, and some other ones, broke. The Observatory has been spared: had it happened by chance or by intention?".

After this, observations were stopped until June 26, 1946.

\section{Conclusions}

For brevity's sake we cite only one observer between those of the post war period, Carlo Moranzino. We have no pages of him with either curious or particular notes to show you. We just could show you thousands of plain pages with observation records written by him. More than 20 thousand of observed star pairs, i.e. the eighth part of the whole observations carried out at Carloforte by 50 people in 80 years!

Acknowledgments. We wish to thank all the people who observed at Carloforte and in the other ILS Stations: every step, even the smallest one, we have taken in understanding the phenomena causing latitude variation is the fruit of a long and assiduous work made by these observers, under uncomfortable work conditions, and often receiving no adequate acknowledgements. 

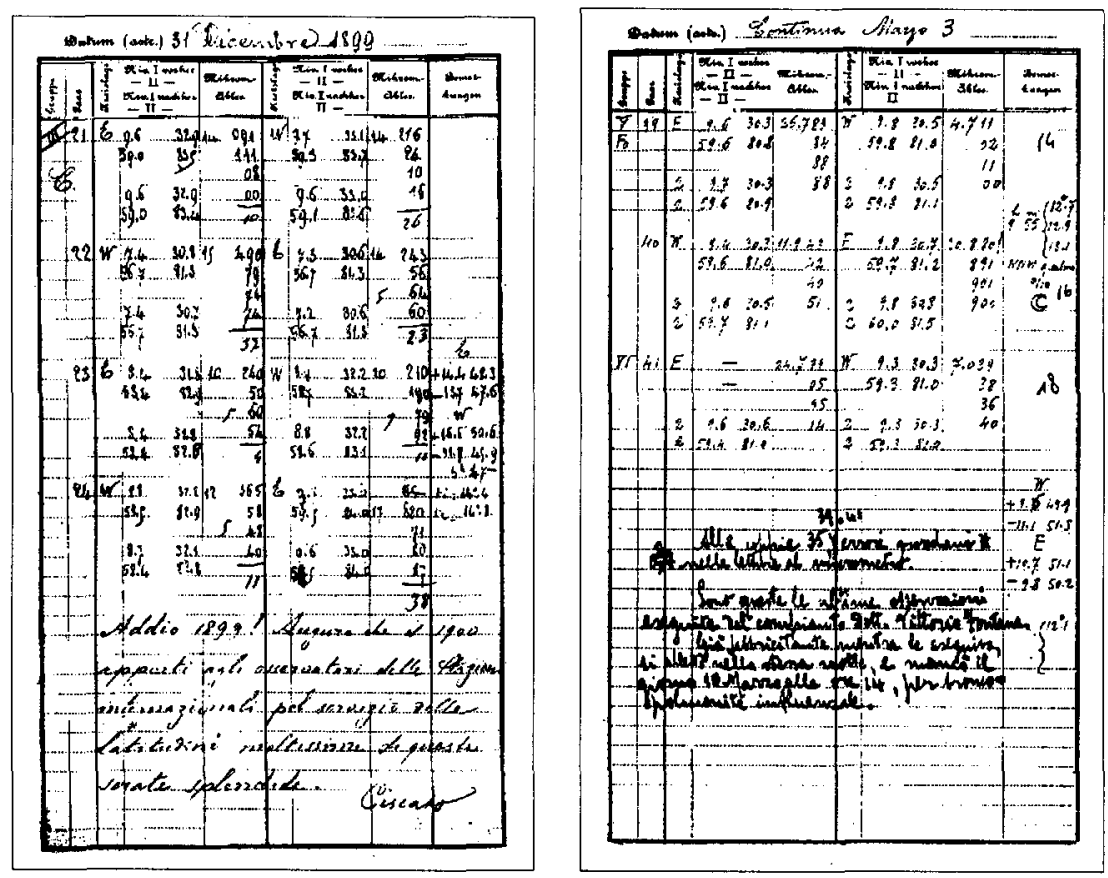

Figure 1. Farewell XIX Century! Farewell Dr. Vittorio Fontana!
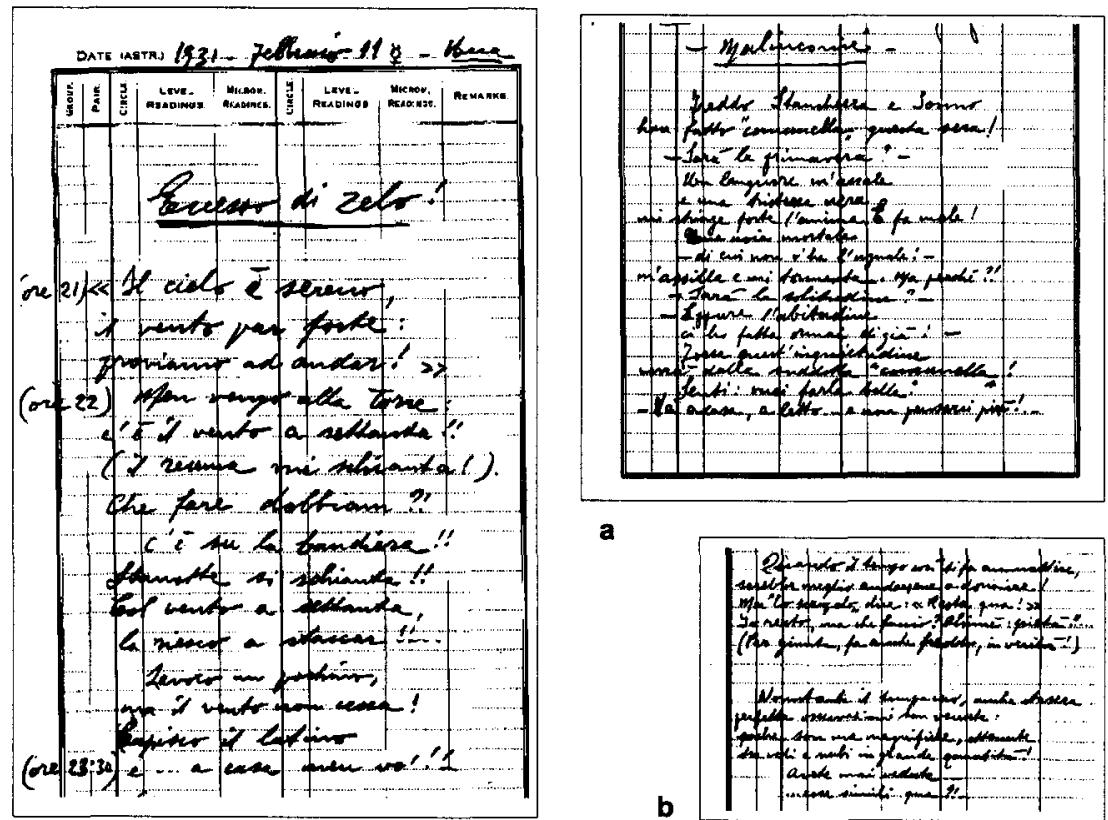

a

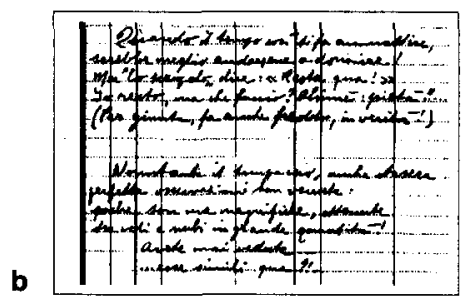

Figure 2. Minimum Anthology of Paolo Vocca (Part I). 

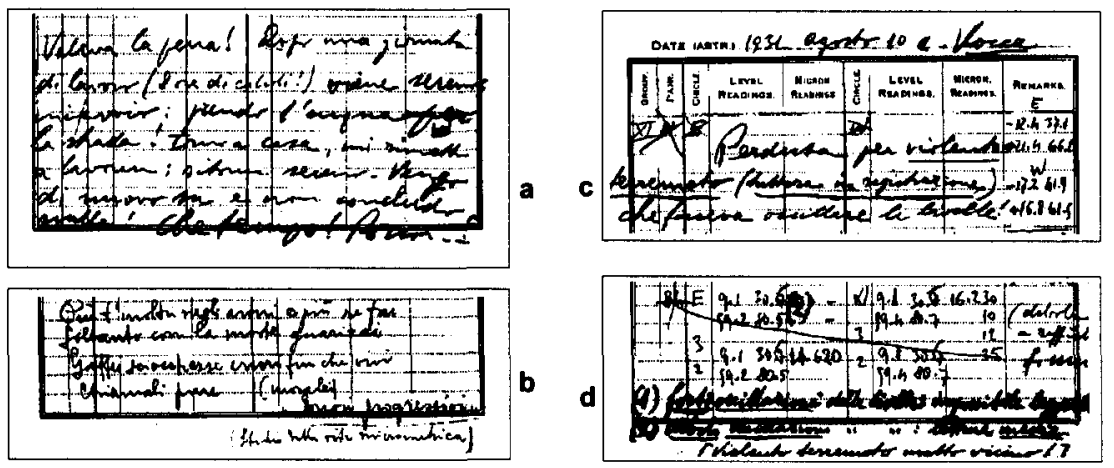

Figure 3. Minimum Anthology of Paolo Vocca (Part II).
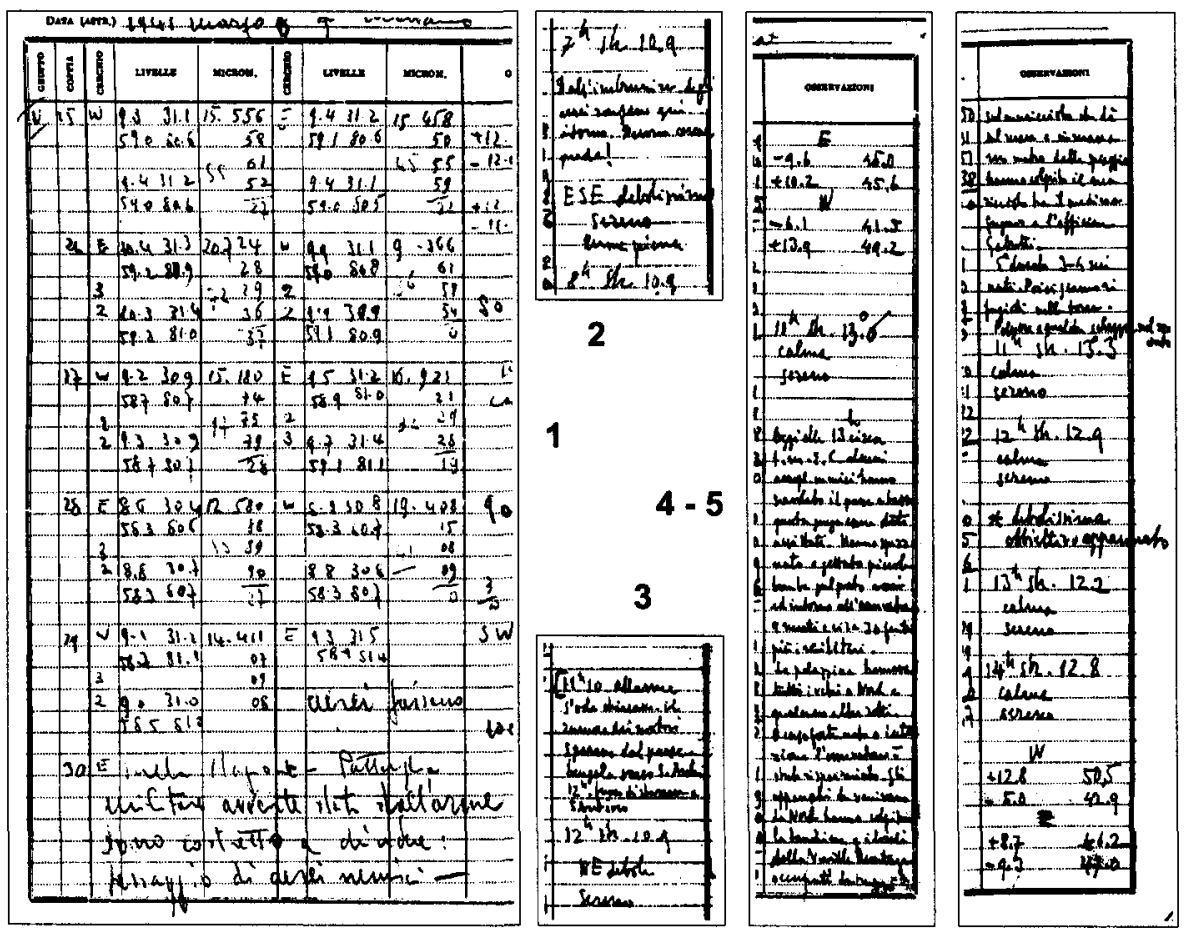

Figure 4. Observers' notes on wartime 1941/43. 